\title{
How to Have Sex in an Epidemic Redux: Reinforcing HIV Prevention in the COVID-19 Pandemic
}

\author{
Peter A. Newman ${ }^{1}$ - Adrian Guta ${ }^{2}$ \\ Published online: 4 June 2020 \\ ○) Springer Science+Business Media, LLC, part of Springer Nature 2020
}

Sexual health is a fundamental determinant of health and wellbeing [1]. All persons-including gay, bisexual, and other men who have sex with men (GBMSM) - have the right to enjoy a safe and pleasurable sexual life with access to comprehensive information, affirmative care, and an enabling legal and sociopolitical environment [1]. The COVID19 pandemic threatens to disrupt HIV programs and global progress toward UNAIDS 90-90-90 targets [2, 3]. The unprecedented repurposing of health services and resources to address COVID-19, along with necessary restrictive public health measures [4], present a spectrum of psychological, sociocultural, structural, and biomedical concerns for sexual health and HIV prevention [5]. In this Note, we draw on lessons learned from four decades of the HIV response with GBMSM communities, and our respective programs of research, to advocate carefully recalibrated, communityengaged approaches to reinforcing HIV prevention in the COVID-19 pandemic.

\section{Sex and Risk in a Pandemic}

Sex in a pandemic is complicated. Key considerations for "safer sex" must address the immediate risks of new coronavirus (SARS-CoV-2) transmission and potential exacerbation of risks for HIV transmission. Sexual transmission of HIV, especially among GBMSM, remains the leading driver of the AIDS epidemic [6]. The integral role of sexual health in many people's lives, and its sociocultural and political ramifications for GBMSM and people living with

Peter A. Newman

p.newman@utoronto.ca

Factor-Inwentash Faculty of Social Work, University of Toronto, 246 Bloor Street West, Toronto, ON M5S 1V4, Canada

2 School of Social Work, University of Windsor, Windsor, ON, Canada
HIV (PLHIV), suggests it is implausible to expect sexual contacts to cease for months or years in response to social distancing and stay-at-home guidelines [7] while awaiting new vaccines and therapeutics [4].

Among the core lessons to emerge from the HIV response is the failure of sex-negative, stigmatizing, and ideologically driven approaches that defy science (e.g., abstinence-based interventions) $[8,9]$. SARS-CoV-2 presents very different transmission and infection risks than HIV; nevertheless, unilateral proscriptions around sex fail to capture the complexity of many GBMSM's sexual lives. They also reflect a concerning disconnection from the sociocultural meanings of sex for a community that has successfully struggled against more than a century of criminalization and repression. The burden of recommendations not to have sex with anyone outside of one's household, and unilateral advice to avoid new partners, are not equally distributed in the context of statesanctioned heterosexuality and the rights it confers in many parts of the world. In many countries, GBMSM are fighting for their very right to exist. Calls to shut down sexual network apps used by GBMSM in the context of the COVID-19 pandemic fail to account for their role in promoting health and social support [10].

\section{Fundamental Considerations for HIV Prevention in the COVID-19 Pandemic}

Immediately following the first author's December 2019 report on a UNICEF-sponsored study of social and structural challenges for HIV prevention among adolescent and young key populations in Southeast Asia [11], the study sponsor and our main partner (Interagency Task Team on Young Key Populations) conducted a rapid survey with 113 respondents aged 18-29 years [12]. Half were MSM, 10\% transgender people, and half PLHIV. In addition to challenges in accessing food supplies (46\%) and loss of income/employment due to pandemic lockdowns (46\%), participants reported 
disruptions in accessing condoms (27\%), HIV testing (26\%), and PrEP (14\%). While 80\% reported receiving COVID-19 information, over two-thirds (68\%) indicated lack of information about measures for PLHIV. Among the 51\% (58/113) on antiretroviral medication (ARV), $22 \%$ reported one-week or less and $29 \%$ a one-month supply; nearly all were unaware if they could access a multi-month prescription [12].

Combination HIV prevention $[13,14]$ in the new pandemic must expand not only to address COVID-19, but to foreground social determinants of health (SDOH), including intersectional discrimination and syndemic burden among GBMSM that produce disparities across HIV prevention and care cascades [15-20]. Pandemic burden is likely to be worsened for GBMSM across intersections of race/ethnicity [16, 21], age [22-24], and immigrant/refugee status [25, 26]. In low- and middle-income countries (LMIC), existing vulnerabilities among GBMSM - as evidenced in our syndemic research on HIV risk in India [27, 28] —are intensified in the pandemic amid overwhelmed healthcare systems [29, 30]. Finally, lack of human rights protections, including in the U.S., more so in $70+$ countries that criminalize same-sex sexual behavior, fuel unstable housing, low-wage employment, barriers in healthcare access, and violence victimization [31, 32], which exacerbate vulnerability in the pandemic and across HIV prevention and care continua [33, 34].

\section{Revisiting the HIV Prevention Cascade}

The COVID-19 pandemic poses considerable threats across the HIV prevention cascade [20]. First, HIV testing motivations and access may be reduced by stay-at-home and physical distancing directives, travel restrictions, perceived risks of SARS-CoV-2 transmission in medical facilities, and clinic repurposing. We anticipate that GBMSM will negotiate sex based on perceived HIV and COVID-19 risks (e.g., only having sex with partners who have been distancing and are assumed to not have been exposed to either). HIV testing may become further stigmatized, including by GBMSM and healthcare providers, due to judgments about the profligacy of (same-sex) sexual activity in the pandemic. However, this ignores different living configurations, sexual cultures and meanings that form an essential context for understanding sexual activity among GBMSM; it also elides situations in which sex is for survival (e.g., sex workers $[35,36]$ ) and nonconsensual (including between people who share a residence) [37]. HIV testing remains a cornerstone of prevention, facilitating access to counselors and providers who can promote behavioral risk reduction strategies. Despite recent investments and positive messaging around HIV testing (fast, easy, and accessible) highlighted in the context of PrEP, testing remains a complex process for many GBMSM in the U.S [38]. and globally [39-42]. This is particularly the case for those whose sexual practices are stigmatized - such as GBMSM who combine sex and drugs [39, 40], and as evidenced in our research with young GBMSM [11], including sex workers, in India [41] and Thailand [42]—and amid structural barriers that limit access to testing [11, 38, 41].

Second, absent HIV testing and diagnosis, GBMSM cannot be provided relevant risk information about HIV and COVID-19 in their communities. HIV testing also serves as a critical conduit for PrEP, or ARV initiation for those who test HIV positive [14, 20]. In contrast to the limitations of abstinence models, including in a pandemic, interventions that promote sexual decision-making and risk reduction strategies are paramount. Beyond the question around why anyone would seek out sex in a pandemic lurks its corollary: "why would anyone want to initiate PrEP in a pandemic?" Yet, this is contrary to the realities of worsening SDOH in the pandemic, which may increase risks for HIV transmission - and the need for PrEP [37]. PrEP access and initiation challenges persist based on insurance status [43], geography and racial disparities [44, 45]. In our 2016 study with GBMSM in Toronto, lack of insurance coverage and pervasive stigma within and outside gay communities were key barriers to PrEP uptake [43]; both are likely to worsen with the economic and social impacts of COVID-19.

Third, the current disruption to health systems and daily life may impact many GBMSM's PrEP adherence, and clinical monitoring. The slow roll-out of PrEP, especially for racialized GBMSM [45] and those in LMIC, is further threatened by potential ARV stock-outs [46] that may aggravate tensions in the context of resource (and ideological) constraints that pit prevention against treatment. Moreover, COVID-19 raises questions about what 'safer sex' means in the era of successful combination prevention, including PrEP and $\mathrm{U}=\mathrm{U}$ (Undetectable $=$ Unstransmittable) [47] . Earlier discussions about 'going back' to condoms if PrEP should fail to deliver may need to be revisited in the context of global treatment disruptions and condom shortages due to the pandemic $[46,48,49]$.

Finally, beyond challenges along the prevention cascade, limitations of the cascade model itself may need to be reevaluated. In addition to critiques of what is sometimes approached as a 'one-size-fits-all' model predicated on linear steps, with all roads leading to PrEP [43], adherence may be threatened by supply chain disruptions, constrained clinic access, and lockdowns in response to COVID-19 [12, 46]. Pandemic stress $[18,50]$ in the absence of psychosocial support and health promotion programs may further threaten PrEP adherence. Some GBMSM may decide to discontinue PrEP due to reduced sexual activity or increased challenges and risks in using PrEP in the pandemic (e.g., attending clinics for required bloodwork). Providers need to be supported by clinical practice guidelines and health insurance companies to respond to these realities by making accommodations 
where possible (e.g., negotiating monitoring requirements, providing longer-term prescriptions) $[3,18]$ and, importantly, maintaining open lines of communication.

\section{Research Directions}

Rapid research, including mixed methods and collaborative approaches, with diverse GBMSM is needed to understand sexual health and broader mental health amidst COVID$19[3,7,18]$. The impact of public health-recommended behavioral changes (physical distancing, stay-at-home), curfews and border lockdowns, and community closures (LGBT + community centers and bars) are crucial topics for inquiry. Investigations should further address the impact of emergency changes in the availability and provision of sexual health screening, access to medication for treatment and prevention, and disruptions across HIV prevention and care continua [3, 7, 47]. The pandemic also demands rapid implementation science approaches to translate innovations in HIV prevention and sexual eHealth services into routine practice-remote HIV and sexual health counseling and home HIV/STI testing [51, 52], and virtual PrEP prescribing, monitoring, and adherence support [53]—along with accelerated research on long-acting injectable PrEP [54, 55]. Structural interventions, such as guaranteed income and healthcare coverage, may decrease reliance on survival sex and ensure PrEP affordability. However, public health interventions are not neutral, and engagement with diverse GBMSM communities is necessary to support acceptability and uptake [56-58].

\section{Conclusion: Community Mobilization and Survival}

Marginalized communities tend to experience lack of confidence and mistrust in the face of public health responses developed without community representation, fueled by ongoing disparities in healthcare access in the absence of human rights protections [32, 59,60]. Lessons learned from successful HIV behavioral and policy responses [61-63] indicate that community-engaged [64, 65], strengths-based [66], and positive psychology approaches [67] that promote solidarity and pride $[33,34]$ may be most effective in reenergizing HIV prevention-as a basic human right and a strategy for community survival. Community mobilization that builds on individual and community strengths among GBMSM and PLHIV in response to emergent challenges for HIV prevention [68] can best promote health in the context of COVID-19 and preparedness for future pandemics.
Acknowledgements PN was supported in part by a Social Sciences and Humanities Research Council of Canada Partnership Grant (MFARRAsia, 895-2019-1020) and the Canadian Institutes of Health Research (303157).

\section{Compliance with Ethical Standards}

Conflict of interest The authors have no conflicts of interest to declare.

\section{References}

1. World Health Organization. Developing sexual health programmes: a framework for action. 2010. Available at: https://apps. who.int/iris/handle/10665/70501?show=full. Accessed April 20, 2020.

2. UNAIDS. Ending AIDS: progress towards the 90-90-90 targets. Joint United Nations Programme on HIV/AIDS. 2017. Available at: https://www.unaids.org/sites/default/files/media_asset/Globa 1_AIDS_update_2017_en.pdf. Accessed May 15, 2020.

3. Shoptaw S, Goodman-Meza D, Landovitz RJ. Collective call to action for HIV/AIDS community-based collaborative science in the era of COVID-19. AIDS Behav. 2020. [published online ahead of print]

4. Lancet. COVID-19: endgames. 2020. Lancet Infect Dis. 2020; 20(5):p511. [Editorial]

5. Lancet. When pandemics collide. Lancet HIV. 2020;7(5):e301. [Editorial]

6. Cohen J, Powderly W, Opal S. Infectious diseases, 4th ed. Elsevier;2017.

7. Alpalhao M, Filipe P. The impacts of isolation measures against SARS-CoV-2 infection on sexual health. AIDS Behav. 2020. [published online ahead of print].

8. Alcorn K. US PEPFAR abstinence and faithfulness funding had no impact on sexual behaviour in Africa. Nam:aidsmap. 2015. Available at: https://www.aidsmap.com/news/feb-2015/us-pepfa r-abstinence-and-faithfulness-funding-had-no-impact-sexua 1-behaviour-africa. Accessed May 15, 2020.

9. Buse K, Hildebrand M, Hawkes S. A farewell to abstinence and fidelity? Lancet Glob Health. 2016;4(9):e599-600.

10. Brennan DJ, Card K, Collict D, et al. How might social distancing impact gay, bisexual, queer, trans and two-spirit men in Canada? AIDS Behav. 2020. [published online ahead of print]

11. UNICEF East Asia \& Pacific. Looking out for adolescents and youth from key populations: formative assessment on the needs of adolescents and youth at risk of HIV - Case studies from Indonesia, the Philippines, Thailand and Viet Nam. 2019. Available at: https://www.unicef.org/eap/reports/looking-out-adolescents-andyouth-key-populations. Accessed May 15, 2020.

12. UNAIDS. Assessing the needs of young key populations during COVID-19 outbreak in Asia and the Pacific. 2020. Available at: https://unaids-ap.org/2020/04/30/assessing-the-needs-of-young -key-populations-during-covid-19-outbreak-in-asia-and-the-pacif ic/. Accessed May 15, 2020.

13. Coates TJ, Richter L, Caceres C. Behavioural strategies to reduce HIV transmission: how to make them work better. Lancet. 2008;372(9639):669-84.

14. Dehne KL, Dallabetta G, Wilson D, et al. HIV Prevention 2020: A framework for delivery and a call for action. Lancet HIV. 2016;3(7):e323-332.

15. Smith B. Intersectional discrimination and substantive equality: a comparative and theoretical perspective. Equal Rights Review. 2016;16:73-102. 
16. Hernandez SM, Sparks PK. Barriers to health care among adults with minoritized identities in the United States, 2013-2017. Am J Public Health. 2020;110(6):857-62.

17. Logie $\mathrm{CH}$, Turan JM. How do we balance tensions between COVID-19 public health responses and stigma mitigation? Learning from HIV research. AIDS Behav. 2020. [published online ahead of print].

18. Harkness A, Behar-Zusman V, Safren SA. Understanding the impact of COVID-19 on Latino sexual minority men in a US HIV hot spot. AIDS Behav. 2020. [published online ahead of print].

19. Quinn KG, Reed SJ, Dickson-Gomez J, Kelly JA. An exploration of syndemic factors that influence engagement in HIV care among Black men. Qual Health Res. 2018;28(7):1077-87.

20. MacNairy ML, EI-Sadr WM, A paradigm shift: focus on the HIV prevention continuum. Clin Infect Dis. 2014;59(1):12-5.

21. Yancy CW. COVID-19 and African Americans. JAMA. 2020. [published online ahead of print].

22. Fredriksen-Goldsen KI, Kim HJ, et al. Health disparities among lesbian, gay, and bisexual older adults: results from a populationbased study. Am J Public health. 2013;103(10):1802-9.

23. Baggaley R, Armstrong A, Dodd Z, Ngoksin E, Krug A. Young key populations and HIV: a special emphasis and consideration in the new WHO Consolidated Guidelines on HIV Prevention, Diagnosis, Treatment and Care for Key Populations. J Int AIDS Soc. 2015;18(2):19438.

24. World Health Organization. Statement - Older people are at highest risk from COVID-19, but all must act to prevent community spread. 2020. Available at: https://www.euro.who.int/en/healt h-topics/health-emergencies/coronavirus-covid-19/statements/ statement-older-people-are-at-highest-risk-from-covid-19,-butall-must-act-to-prevent-community-spread. Accessed May 15, 2020.

25. Orcutt M, Patel P, Burns R, et al. Global call to action for inclusion of migrants and refugees in the COVID-19 response. Lancet. 2020;395(102350):1482-3.

26. Ross J, Diaz CM, Starrels JL. The disproportionate burden of COVID-19 for immigrants in the Bronx, New York. JAMA Intern Medicine. 2020. [published online ahead of print]

27. Chakrapani V, Kaur M, Newman PA, Mittal S, Kumar R. Syndemics and HIV-related sexual risk among men who have sex with men in India: influences of stigma and resilience. Cult Health Sex. 2019;21(4):416-31.

28. Chakrapani V, Kaur M, Tsai AC, Newman PA, Kumar R. The impact of a syndemic theory-based intervention on HIV transmission risk behaviour among men who have sex with men in India: pretest-posttest non-equivalent comparison group trial. Soc Sci Med. 2020:112817. [published online ahead of print].

29. Lancet. India under COVID-19 lockdown. Lancet. 2020;395(10233):1315.

30. The Wire Science. [Editorial]. Mumbai runs out of hospital beds for suspected COVID-19 patients, starts a 'waitlist'. 2020. Available at: https://science.thewire.in/health/mumbai-covid-19-hospi tal-beds/. Accessed May 15, 2020.

31. Human Rights Watch. Human rights dimensions of COVID19 response. 2020. Available at: https://www.hrw.org/ news/2020/03/19/human-rights-dimensions-covid-19-response. Accessed May 15, 2020.

32. Gostin LO, Meier BM, Huffstetler H. Human rights in global health governance. Glob Health Gov. 2018;12(1):4-10.

33. Haynes, S. 'There's always a rainbow after the rain.' Challenged by coronavirus, LGBTQ communities worldwide plan digital pride celebrations. Time Magazine. 2020. Available at: https://time.com/5814554/coronavirus-lgbtq-community-pride/. Accessed May 15, 2020.

34. UNAIDS. Press statement: UNAIDS calls on governments to stop arbitrary and discriminatory arrests of LGBTI people and to protect their human rights. 2020. Available at: https://www. unaids.org/sites/default/files/20200515_PS_IDAHOT_en.pdf. Accessed May 15, 2020.

35. Baral S. Male sex workers: practices, contexts, and vulnerabilities for HIV acquisition and transmission. Lancet. 2015;385(9964):260-73.

36. Newman PA, Rhodes F, Weiss R. Correlates of sex trading among drug-using men who have sex with men. Am J Public Health. 2004;94(11):1998-2003.

37. Braksmajer A, Walters SM, Crean HF, Stephenson R, McMahon JM. Pre-exposure prophylaxis use among men who have sex with men experiencing partner violence. AIDS Behav. 2020. [published online ahead of print].

38. Levy ME, Wilton L, Phillips G, et al. Understanding structural barriers to accessing HIV testing and prevention services among black men who have sex with men (BMSM) in the United States. AIDS Behav. 2014;18:972-96.

39. Kwan TH, Lee SS. (2019). Bridging awareness and acceptance of Pre-exposure prophylaxis among men who have sex with men and the need for targeting chemsex and HIV testing: cross-sectional survey. JMIR Public Health and Surveil. 2019;5(3):e13083.

40. Karamouzian M, Johnson C, Kerr T. Public health messaging and harm reduction in the time of COVID-19. Lancet Psychiatry. 2020;7(5):390-1.

41. Woodford MR, Chakrapani V, Newman PA, Shunmugam M. Barriers and facilitators to voluntary HIV testing uptake among communities at high risk of HIV exposure in Chennai. India Glob Public Health. 2016;11(3):363-79.

42. Logie CH, Newman PA, Weaver J, Roungkraphon S, Tepjan S. HIV-related stigma and HIV prevention uptake among young men who have sex with men and transgender women in Thailand. AIDS Patient Care STDs. 2016;30(2):92-100.

43. Newman PA, Guta A, Lacombe-Duncan A, Tepjan S. Clinical exigencies, psychosocial realities: negotiating HIV pre-exposure prophylaxis beyond the cascade among gay, bisexual and other men who have sex with men in Canada. J Int AIDS Soc. 2018;21(11):e25211.

44. Jenness SM, Maloney KM, Smith DK, et al. Addressing gaps in HIV Preexposure Prophylaxis care to reduce racial disparities in HIV incidence in the United States. Am J Epidemiol. 2018;188(4):743-52.

45. Kanny D, Jefferies WL IV, Chapin-Bardales J, et al. Morbidity and Mortality Weekly Report (MMWR): Racial/Ethnic Disparities in HIV Preexposure Prophylaxis Among Men Who Have Sex with Men - 23 Urban Areas, 2017. Centers for Disease Control and Prevention; 2019. Available at: https://www.cdc.gov/mmwr/volum es/68/wr/mm6837a2.htm\#contribAff. Accessed May 15, 2020.

46. UNAIDS. What people living with HIV need to know about HIV and COVID-19. 2020. Available at: https://www.unaids.org/en/ resources/documents/2020/HIV_COVID-19_brochure. Accessed April 21, 2020.

47. Prevention Access Campaign. Consensus statement: risk of sexual transmission of HIV from a person living with HIV who has an undetectable viral load. 2020. Available at: https://www.preve ntionaccess.org/consensus. Accessed April 21, 2020.

48. Pattillo A. The global condom shortage is already upon us: How coronavirus is crippling the contraceptive industry. Inverse.com; 2020. Available at: https://www.inverse.com/mind-body/the-globa 1-condom-shortage-is-already-upon-us-how-coronavirus-is-cripp ling-the-contraceptive-industry. Accessed May 15, 2020.

49. UNAIDS. Condoms and lubricants in the time of COVID-19: Sustaining supplies and people-centred approaches to meet the need in low- and middle-income countries. 2020. Available at: https ://www.unaids.org/sites/default/files/media_asset/condoms-lubri cants-covid19_en.pdf. Accessed May 15, 2020. 
50. Galea S, Merchant RM, Lurie N. The mental health consequences of COVID-19 and physical distancing: the need for prevention and early intervention. JAMA Intern Med. 2020. [published online ahead of print].

51. Carey MP, Dunne EM, Norris A, et al. Telephone-delivered mindfulness training to promote medication adherence and reduce sexual risk behavior among persons living with HIV: an exploratory clinical trial. AIDS Behav. 2020;24:1912-28.

52. Wang Z, Lau JTF, Ip M, et al. A randomized controlled trial evaluating efficacy of promoting a home-based HIV self-testing with online counseling on increasing HIV testing among men who have sex with men. AIDS Behav. 2018;22:190-201.

53. Touger R, Wood BR. A review of telehealth innovations for HIV Pre-exposure prophylaxis (PrEP). Curr HIV/AIDS Rep. 2019;16:113-9.

54. Parsons JT, Rendina HJ, Whitfield THF, et al. Familiarity with and preferences for oral and long-acting injectable HIV Pre-exposure Prophylaxis (PrEP) in a national sample of gay and bisexual men in the U.S. AIDS Behav. 2016;20:1390-9.

55. Clement ME, Kofron R, Landovitz RJ. Long-acting injectable cabotegravir for the prevention of HIV infection. Curr Opin HIV AIDS. 2020;15(1):19-26.

56. Guta A, Murray SJ, Gagnon M. HIV, viral suppression and new technologies of surveillance and control. Body Soc. 2016;22(2):82-107.

57. McClelland A, Guta A, Gagnon M. The rise of molecular HIV surveillance: implications on consent and criminalization. Crit Public Health. 2019. [published online ahead of print].

58. Newman PA, Rubincam C, Slack C, et al. Towards a science of community stakeholder engagement in biomedical HIV prevention trials: an embedded four-country case study. PLoS ONE. 2015;10(8):e0135937.

59. Driedger SM, Maier R, Jardine C. 'Damned if you do, and damned if you don't': communicating about uncertainty and evolving science during the H1N1 influenza pandemic. J Risk Res. 2018:1-19. DOI: $10.1080 / 13669877.2018 .1459793$
60. O'Sullivan TL, Phillips KP. From SARS to pandemic influenza: the framing of high-risk populations. Nat Hazards. 2019;98(1):103-17.

61. Berkowitz R, Callen M, Dworkin R. How to have sex in an epidemic: one approach. NYC: News from the Front Publications; 1983.

62. Escoffier J. The invention of safer sex: vernacular knowledge, gay politics and HIV prevention. Berkeley J Sociology. 1998;43:1-30.

63. Valdiserri RO, Holtgrave DR. Responding to pandemics: what we've learned from HIV/AIDS. AIDS Behav. 2020. [published online ahead of print].

64. UNAIDS. Policy Brief: the greater involvement of people living with HIV (GIPA). 2014. https://vpwas.com/wp-content/uploa ds/2014/10/d96596c4b961f1929dc8687ace6c44e6.pdf. Accessed May 18, 2020.

65. Trapence G, Collins C, Avrett S, et al. From personal survival to public health: community leadership by men who have sex with men in the response to HIV. Lancet. 2012;380(9839):400-10.

66. Herrick AL, Stall R, Goldhammer H, Egan JE, Mayer KH. Resilience as a research framework and as a cornerstone of prevention research for gay and bisexual men: theory and evidence. AIDS Behav. 2014;18(1):1-9.

67. Hefferon K, Boniwell P. Positive psychology: theory, research and applications. Berkshire, UK: Open University Press; 2011.

68. UNAIDS. Press Statement. UNAIDS urges governments to ensure that HIV service providers from community-led organizations are recognized as essential service providers in the context of COVID-19. 2020. Available at: https://www.unaids.org/sites/ default/files/20200518-statement-on-essential-community-ledservices_en.pdf. Accessed May 18, 2020.

Publisher's Note Springer Nature remains neutral with regard to jurisdictional claims in published maps and institutional affiliations. 